\title{
The cognitive contexts of beliefs about the healthiness of meat
}

\author{
Emma Lea ${ }^{1, *}$ and Anthony Worsley ${ }^{2}$ \\ ${ }^{1}$ Department of Public Health, Adelaide University, Adelaide, South Australia 5005, Australia: \\ ${ }^{2}$ School of Health Sciences, Deakin University, Burwood, Victoria 3125, Australia
}

Submitted 20 November 2000: Accepted 15 June 2001

\begin{abstract}
Objective: The overall aim of this study was to examine a variety of belief and demographic factors that are associated with the perception that meat is intrinsically unhealthy.

Design: State-wide survey (written questionnaire) that included questions on meat and nutrition beliefs, perceived barriers and benefits of vegetarian diets, personal values, number of vegetarian friends and family members, and use and trust of health/nutrition/food information sources.

Setting: South Australia.

Subjects: Six hundred and one randomly selected South Australians and 106 nonrandomly selected vegetarians and semi-vegetarians.

Results: For all respondents considered as a group, the most important predictors of the belief that meat is intrinsically unhealthy were the perceived benefits of vegetarian diets (all positive predictors). These included: (1) the perceived links between vegetarianism, peace and increased contentment; (2) animal welfare and environmental benefits; and (3) health benefits. There were differences between different dietary groups however. For non-vegetarians, social concerns about vegetarianism (positive) were most important, followed by health and non-health benefits (positive) of vegetarianism. Red meat appreciation was the strongest (positive) predictor for vegetarians, with health benefits of vegetarianism (positive) and education (negative predictor) also important.

Conclusions: The implications of the findings for health and other issues are discussed. Judgements about the healthiness of meat are likely to be related to moral and environmental beliefs and, for non-vegetarians, to social concerns about vegetarianism, in addition to health beliefs. These need to be considered if any attempts are made to influence meat consumption.
\end{abstract}

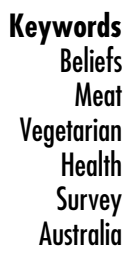

Meat is a controversial food: it may be considered to provide health benefits or to be detrimental to one's health, often depending on the amount consumed. Red meat provides $\mathrm{B}$ vitamins, minerals and protein, and in this way may contribute positively to the $\operatorname{diet}^{1}$. However, recent nutritional recommendations suggest that only limited amounts of (low-fat) meat (no more than 80 to $100 \mathrm{~g}$ per day) should be consumed ${ }^{2-4}$.

Compared with meat-centred diets, plant-based diets contain less saturated fat, animal protein and cholesterol, and are higher in folate, fibre, antioxidants, phytochemicals and carotenoids 5,6 . People who choose not to eat any meat have lower mean body mass, lower total plasma cholesterol concentrations, and substantially lower mortality from ischaemic heart disease ${ }^{7,8}$. All-cause mortality rates are also lower. For example, the Oxford Vegetarian
Study found that the ratio for all-cause mortality for vegetarians compared with meat eaters was 0.80 , after adjusting for smoking, social class and body mass index 9 .

Diets low in meat may entail the risk of not meeting the needs for some nutrients, particularly iron, zinc and vitamin $\mathrm{B}_{12}{ }^{10,11}$. However, despite mean serum ferritin levels being lower, clinical anaemia does not appear to be more common in those who consume no meat than among omnivores ${ }^{10,12}$, at least in Western countries ${ }^{13}$.

Consumers are not always presented with accurate dietary information with which they can make a balanced judgement of the healthiness of foodstuffs such as meat. Furthermore, even if they were, consumers are influenced by other factors in addition to knowledge. This paper will examine the factors that predict negative beliefs about the healthiness of meat. 
The score Meat is Unbealthy forms the basis for this analysis. It was obtained from the sum of respondents' level of agreement with four statements: (1) Meat causes heart disease; (2) Meat causes cancer; (3) Red meat such as beef or lamb is fattening; and (4) Meat such as beef and lamb is unhealthy to eat. These statements were derived from a factor analysis of a larger number of beliefs about meat, as discussed below. These four beliefs are specifically about perceptions of the intrinsic unhealthiness of meat that tend to be unsupported by the scientific literature. For example, not eating meat is associated with a decreased risk of heart disease, but it is unlikely that meat causes heart disease. Instead, because of the emphasis on consumption of fruits, vegetables and whole grains, vegetarians may consume a diet lower in fat by eating fewer fatty foods from sources other than meat, such as cakes and oils. Nonetheless, consumers' perceptions are relevant for the promoters of both meat and plant-based diets. They offer important insights into consumers' attitudes about meat.

Health is not the sole reason given by consumers for the reduction or avoidance of meat consumption. Animal welfare and environmental issues are also important. For example, it is argued that a reduction in meat consumption would result in a decrease in methane production, soil erosion and water usage $\mathrm{e}^{14-17}$.

\section{Factors associated with beliefs}

Beliefs influence attitudes, which in turn influence behaviour $^{18}$. Attitudes and beliefs about meat are important determinants of its consumption ${ }^{19-21}$. However, the social-cognitive origins of meat-related beliefs and attitudes are obscure. Therefore the present study examined a number of factors that may be associated with negative beliefs about meat. These include other beliefs about meat and about nutrition, barriers to and benefits of vegetarianism, number of vegetarian friends and family, personal values, use of and trust in information sources, and demography.

People often face difficulties or barriers when they try to change their food consumption ${ }^{22,23}$. These barriers may be practical or attitudinal. It has been argued that it is only when the benefits of change outweigh the barriers that a change in behaviour occurs ${ }^{24-26}$. It may be expected that this is the case for vegetarians and other adherents to plant-based diets. People, like some vegetarians, who hold beliefs about the unhealthiness of meat, may also hold particular beliefs about the benefits of, and barriers to, plant-based foods. We hypothesised that the perceived benefits of vegetarian diets would be positively associated with Meat is Unhealthy (hypothesis 1) but the perceived barriers to the adoption of vegetarian diets would be negatively associated (hypothesis 2).

\section{Methods}

\section{Procedure}

One thousand people were randomly selected from the South Australian population by using the Marketing Pro software package (April 1999 version), containing the full list of residences from the White Pages telephone directory. A 12-page booklet (200 items) was mailed to each person in the sample along with a cover letter and a freepost envelope. Dillman's ${ }^{27}$ recommended methods for surveys formed the basis of the questionnaire design and administration. A number of follow-up reminders were mailed to the sample to ensure the best possible response rate, as described elsewhere ${ }^{19}$.

Due to the small number of vegetarians $(n=9)$ in the random sample, a small non-random sample $(n=106)$ of vegetarians and semi-vegetarians was included in the survey. This was done in order to ensure our sample contained statistically viable numbers for comparisons between people with high meat consumption (present in large numbers in the random sample) and people with very low or nil meat consumption (not present in adequate numbers in the random sample). The sample was selected by placing advertisements in health food stores, vegetarian cafés and restaurants, and at Adelaide University; by distributing questionnaires at an environmental fair; and by word-of-mouth.

\section{Questionnaire}

The questionnaire was formed from interviews with 15 vegetarians; from the literature ${ }^{20,28-31}$; and from three food choice questionnaires. The existing questionnaires were an Australian survey on meat consumption and attitudes $^{32}$; the Institute of European Food Studies (IEFS) European Union survey on attitudes to food, health and nutrition $^{33}$; and New Zealand and Australian surveys of concerns about food ${ }^{34}$.

The questionnaire contained several sections that included the following.

1. Twenty items about beliefs about meat (some of which were based on the questionnaire of Worsley et $a l .{ }^{32}$ ), both negative and positive, were measured. Respondents answered by indicating their level of agreement with each belief on a five-point Likert-type scale, ranging between strongly disagree and strongly agree. The beliefs included 'I love to eat red meat such as beef, veal or lamb', 'Meat is necessary in the adult human diet', 'When I eat out to celebrate a social occasion, I usually eat some kind of red meat', 'Red meat is very expensive', 'I prefer to eat red meat more than fruit or vegetables' and 'Meat production is cruel to animals'. The four beliefs about the unhealthiness of meat, as described in the Introduction, were also included in this section.

2. Perceived benefits of vegetarian diets (24 items) were 
measured, parts of which were modelled on the IEFS survey $^{33}$. Respondents indicated their level of agreement or disagreement with each benefit on a fivepoint scale.

3. Thirteen demographic variables were measured, including age, sex, occupation, education, marital status, nature of household, income, religion and ethnicity.

The remaining sections were about respondents' frequency of use of and trust in sources of information about food, nutrition and health; recall of promotion of meat and vegetarianism by these information sources; beliefs about nutrition (such as 'Diet is important in preventing illness and disease'); self-identified dietary status (vegetarian, semi-vegetarian, non-vegetarian); frequency of meat and fish consumption; number of vegetarian friends and family; perceived barriers to vegetarian diets; and personal values. Analyses of these sections will be reported in depth elsewhere.

\section{Data analysis}

Principal components analysis with varimax rotation was performed on the 20 beliefs about meat items. Three factors emerged that were provisionally named as: (1) Meat is a Necessary Dietary Component, (2) Red Meat Appreciation and (3) Anti-Meat. The third factor consisted of the four Meat is Unbealthy beliefs, each with a factor loading of 66 and over, and a number of other nonhealth-related items, with factor loadings of 53 and under. The four Meat is Unhealthy beliefs were summed together for use as a dependent variable because (1) they were the highest loading items on the factor, noticeably higher than the fifth and lower items; (2) together they had high internal reliability (Cronbach's alpha of 0.85); and (3) they formed an easily interpretable set of beliefs.

Cross-tabulation analyses by sex and dietary group (non-vegetarian, semi-vegetarian, vegetarian) were performed for each of the four items incorporated in the Meat is Unbealthy score. Respondents classified themselves as 'non-vegetarian', 'semi-vegetarian' or 'vegetarian'. There were no definitions of these categories provided, in order for respondents' own perceptions of which category they belonged in to be taken into account. However, as we also measured frequency of meat and fish consumption, we were able to examine the relation between selfperception and actual behaviour. The self-identified semivegetarians had reduced meat consumption compared with non-vegetarians (for example, 49\% never or rarely ate red meat), and the majority of self-identified vegetarians $(85 \%)$ never ate red or white meat, fish or seafood.

Principal components analyses with varimax rotation were performed on the correspondents' responses to the main sections of the questionnaire, namely beliefs about meat, barriers to vegetarian diets, benefits of vegetarian diets, personal values, use of information sources and trust in information sources. However, only the principal components analysis results relating to the benefits of vegetarianism are reported here, since they were the most frequently occurring factors in the results of the regression analyses of the Meat is Unhealthy score (below).

Stepwise multiple regression analyses of the Meat is Unhealthy score were run with factor scores derived from the above principal components analyses, the demographic variables, the respondents' recall of the promotion of meat and vegetarianism, beliefs about nutrition, and numbers of vegetarian friends and family. There were small numbers of respondents who had missed some key items of the questionnaire, and therefore analyses using both list-wise and pair-wise methods of managing missing cases were run to ensure the results were not methodological artefacts. Results of the pair-wise analyses are presented here. Regression analyses were also conducted within each dietary group. All analyses were conducted with SPSS statistical software (version 10) using an alpha level of 0.05 for all statistical tests.

\section{Results}

\section{Response and respondent characteristics}

Approximately $71 \%$ of the randomly selected subjects who could be contacted answered the questionnaire $(n=$ $603)$, with two questionnaires being unusable. About $15 \%$ of the sample was unable to be contacted because their addresses had changed since the Marketing Pro data were collected or were incomplete, or they could not be contacted by telephone. Together with the 106 nonrandomly selected vegetarians and semi-vegetarians, the total number of usable questionnaires was 707 .

Table 1 lists some of the demographic characteristics of the non-randomly selected sample (mostly vegetarians), the randomly selected (mostly omnivores) sample, and the general South Australian population, as obtained from the Basic Community Profile of the 1996 Census of Population and Housing ${ }^{35}$. Comparisons were made for sex, age, country of birth, employment status and marital status, as these were the variables in the Basic Community Profile that were directly comparable to the demographic variables in the survey. There were some differences between the groups. The main biases in the randomly selected sample were under-representation of 19-24 year olds and over-representation of 45-64 year olds and married people compared with the Census data. The nonrandom group was younger than the random and Census groups. This is in accordance with findings from surveys that the prevalence of vegetarianism is higher amongst younger people $\mathrm{e}^{36-38}$. Compared with the random sample and the Census data, fewer of the non-random sample were employed full-time, married or widowed/divorced. Unemployment figures were similar for the non-random sample and the Census data. However, the random 
Table 1 Demographic characteristics of the randomly selected general population survey respondents, the non-randomly selected vegetarian and semi-vegetarian sample and the South Australian population as a whole, as obtained from the Basic Community Profile of the 1996 Census of Population and Housing

\begin{tabular}{|c|c|c|c|}
\hline & $\begin{array}{l}\text { Non-random survey } \\
\text { respondents (\%) }\end{array}$ & $\begin{array}{l}\text { Random survey } \\
\text { respondents (\%) }\end{array}$ & 1996 Census (\%) \\
\hline \multicolumn{4}{|l|}{ Sex } \\
\hline Female & 54.7 & 56.8 & 51.4 \\
\hline Male & 45.3 & 43.2 & 48.6 \\
\hline \multicolumn{4}{|l|}{ Age $^{*}$} \\
\hline $15-18$ years & 3.8 & 0.7 & 6.7 \\
\hline $19-24$ years & 27.4 & 3.8 & 10.5 \\
\hline $25-44$ years & 48.1 & 40.9 & 38.0 \\
\hline $45-64$ years & 17.0 & 33.4 & 26.9 \\
\hline $65+$ years & 3.8 & 21.2 & 17.4 \\
\hline \multicolumn{4}{|l|}{ Country of birth } \\
\hline Australia & 71.4 & 74.2 & 75.5 \\
\hline Other country & 28.6 & 25.8 & 24.5 \\
\hline \multicolumn{4}{|l|}{ Employment status $†$} \\
\hline Employed full-time & 17.9 & 29.8 & 34.2 \\
\hline Employed part-time & 17.9 & 17.6 & 17.1 \\
\hline Unemployed & 7.5 & 1.7 & 6.1 \\
\hline \multicolumn{4}{|l|}{ Marital status } \\
\hline Married $\ddagger$ & 38.5 & 69.0 & 54.0 \\
\hline Widowed/divorced & 10.6 & 17.4 & 17.2 \\
\hline
\end{tabular}

Note that only directly comparable items could be included in this table.

* No minimum age prerequisite was specified for participation in the survey; however, as the survey was addressed to a person listed in the phone directory, it was expected that younger people (particularly under-18s) would be less likely to participate. As no one under 15 years old participated in the survey, the Census data for age excludes those under 15 (i.e. the percentages are expressed as a percentage of those aged 15 and over). The Census percentages do not total $100 \%$ due to the inclusion of overseas visitors (with no age stated) in the total number of persons.

† The survey percentages for 'employed full-time' and 'employed part-time' exclude those self-employed, as there was a separate category for the latter, comprising $7.3 \%$ of the sample. However, the Census data included the self-employed with full-time or part-time employed. Therefore, the survey 'employed full-time' and 'employed part-time' categories are an underestimate.

$\ddagger$ In the survey, 'married' includes 'living together', whereas in the Census it does not. Therefore, the survey figure is an overestimate.

sample contained a lower proportion of unemployed people.

\section{Meat is Unbealtby items}

All of the differences between the dietary groups for both men and women for the four items loading on Meat is Unbealthy were highly statistically significant (Table 2). Generally, the percentage of respondents agreeing with the various statements was lowest among non-vegetarians and highest among vegetarians, with semi-vegetarians intermediate. For example, 6\% of female non-vegetarians agreed that 'Meat causes heart disease', compared with
$24 \%$ of semi-vegetarians and $46 \%$ of vegetarians. More non-vegetarians, both male and female, agreed with the belief that 'Red meat such as beef or lamb is fattening' than with any other belief statement (10\% of females agreed compared with $12 \%$ of male non-vegetarians), while $8 \%$ of non-vegetarian men and $6 \%$ of women agreed with 'Meat causes heart disease'. For female semivegetarians, the highest agreement was with the statement that 'Meat causes heart disease' (24\%), whereas for males it was with 'Red meat such as beef or lamb is fattening' (39\%). Vegetarians agreed most strongly with 'Meat such as beef and lamb is unhealthy to eat' (56\% of

Table 2 Description of the Meat is Unhealthy score, obtained by summing respondents' answers to the four variables, and the percentage of non-vegetarian (Non-veg.), semi-vegetarian (Semi-veg.) and vegetarian men and women who agreed with the variables

\begin{tabular}{|c|c|c|c|c|c|c|c|c|}
\hline \multirow[b]{3}{*}{ Meat is Unhealthy } & \multicolumn{8}{|c|}{$\%$ Agree (\% Don't know) } \\
\hline & \multicolumn{4}{|c|}{ Women } & \multicolumn{4}{|c|}{ Men } \\
\hline & Non-veg. & Semi-veg. & Vegetarian & $P$ & Non-veg. & Semi-veg. & Vegetarian & $P$ \\
\hline Meat causes heart disease & $6(32)$ & $24(33)$ & 46 (32) & 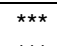 & $8(40)$ & $33(50)$ & $65(23)$ & 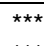 \\
\hline Meat causes cancer & $1(32)$ & $18(42)$ & $42(35)$ & $\star \star * *$ & $4(39)$ & $21(58)$ & $50(40)$ & *** \\
\hline Red meat such as beef or lamb is fattening & $10(11)$ & $9(31)$ & 37 (32) & $\star \star \star *$ & $12(19)$ & 39 (22) & 55 (23) & *** \\
\hline Meat such as beef and lamb is unhealthy to eat & $2(8)$ & $12(24)$ & $56(13)$ & $\star \star \star *$ & $4(9)$ & $33(28)$ & 73 (13) & 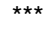 \\
\hline
\end{tabular}

Women - non-vegetarian $n=306$, semi-vegetarian $n=34$, vegetarian $n=55$; Men - non-vegetarian $n=234$, semi-vegetarian $n=21$, vegetarian $n=48$ (respondents identified their own dietary status).

$\star * \star, P<0.001$. 
Table 3 Results of principal components analysis of benefits of vegetarianism

\begin{tabular}{lr}
\hline Factor and items & Factor loadis \\
\hline Factor 1: Peace and Contentment Benefits of Vegetarianism & \\
Eigenvalue: 13.07 & 71 \\
Cronbach's alpha: 0.96 & 70 \\
Percentage of variance: $54.4 \%$ & 69 \\
Help the feminist cause & 67 \\
Be less aggressive & 66 \\
Be more content with myself & 64 \\
Help create a more peaceful world & 57 \\
Satisfy my religious and/or spiritual needs & 55 \\
Have a tastier diet & 54 \\
Have a better quality of life & 49 \\
Be fit & 48 \\
Save money & 47 \\
Have plenty of energy & 46 \\
Eat a greater variety of interesting foods & 45 \\
Lower my chances of getting food poisoning & 41 \\
Increase my control over my own health & 38 \\
Stay healthy & 38 \\
Increase the efficiency of food production & 37 \\
Live longer & 5 \\
Decrease hunger in the Third World & \\
Help the environment &
\end{tabular}

Factor 2: Health Benefits of Vegetarianism

Eigenvalue: 1.65

Cronbach's alpha: 0.95

Percentage of variance: $6.9 \%$

Prevent disease in general (e.g. heart disease, cancer)

Decrease saturated fat intake in my diet $\quad 74$

Control my weight $\quad 71$

Stay healthy $\quad 67$

Live longer $\quad 67$

$\begin{array}{ll}\text { Increase my control over my own health } & 61\end{array}$

58

$\begin{array}{ll}\text { Have a better quality of life } & 57\end{array}$

Have plenty of energy $\quad 57$

Eat more fruit and vegetables $\quad 54$

Eat a greater variety of interesting foods 48

Be healthier by decreasing my intake of chemicals, steroids and antibiotics that are found in meat 46

Have a tastier diet $\quad 45$

Be more content with myself $\quad 41$

Lower my chances of getting food poisoning 36

Factor 3: Animal Welfare, Environmental and Hunger Benefits of Vegetarianism

Eigenvalue: 1.10

Cronbach's alpha: 0.95

Percentage of variance: $4.6 \%$

Help animal welfare/rights

作

Help the environment $\quad 75$

Decrease hunger in the Third World $\quad 75$

Be healthier by decreasing my intake of chemicals, steroids and antibiotics that are found in meat 57

Help create a more peaceful world $\quad 54$

Lower my chances of getting food poisoning 44

Eat a greater variety of interesting foods $\quad 40$

Increase my control over my own health

Have a tastier diet $\quad 38$

$\begin{array}{ll}\text { Be more content with myself } & 37\end{array}$

Satisfy my religious and/or spiritual needs $\quad 36$

Have a better quality of life $\quad 36$

${ }^{*}$ Factor loadings are in one-hundredth units. The factor loadings and the explained variances are based on the rotated solution.

females agreed and $73 \%$ of males). More men agreed with the various statements than women in all dietary groups. Of note was the high level of respondents of all dietary persuasions who were unsure whether they agreed or not that meat causes heart disease and cancer.

\section{Benefits of vegetarianism}

The first component (Table 3) consisted of feminist and peaceful (both inner peace and external peace) benefits of vegetarianism, along with taste and health benefits (Factor 1, Peace and Contentment Benefits of Vegetarianism). 
Table 4 Stepwise multiple regression analysis of Meat is Unhealthy

\begin{tabular}{|c|c|c|c|}
\hline & Beta & $P$ & $R^{2}(\%)$ \\
\hline \multicolumn{4}{|l|}{ All respondents } \\
\hline Peace and contentment benefits of vegetarianism & 0.39 & $\star \star * \star$ & 16.3 \\
\hline Animal welfare, environmental and hunger benefits of vegetarianism & 0.36 & $\star \star * *$ & 31.3 \\
\hline Health benefits of vegetarianism & 0.31 & 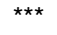 & 42.5 \\
\hline Male & 0.16 & $\star * \star *$ & 45.1 \\
\hline Number of vegetarian family members & 0.13 & 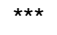 & 46.5 \\
\hline Final $R^{2}(\%)$ & & & 46.5 \\
\hline \multicolumn{4}{|l|}{ Non-vegetarian } \\
\hline Social concerns about vegetarianism & 0.19 & 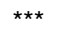 & 6.3 \\
\hline Health benefits of vegetarianism & 0.26 & 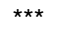 & 11.6 \\
\hline Animal welfare, environmental and hunger benefits of vegetarianism & 0.23 & $\star \star \star *$ & 14.1 \\
\hline Peace and contentment benefits of vegetarianism & 0.27 & 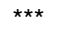 & 17.9 \\
\hline Male & 0.18 & ** & 19.6 \\
\hline Diet is important in preventing illness and disease & 0.15 & $\star \star \star *$ & 21.3 \\
\hline Recall of the promotion of meat & -0.17 & 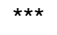 & 22.9 \\
\hline Recall of the promotion of vegetarianism & 0.12 & $\star \star *$ & 24.2 \\
\hline Final $R^{2}(\%)$ & & & 24.2 \\
\hline \multicolumn{4}{|l|}{ Semi-vegetarian } \\
\hline Income & -0.42 & $\star \star$ & 20.9 \\
\hline Universal values & 0.41 & ** & 37.5 \\
\hline Final $R^{2}(\%)$ & & & 37.5 \\
\hline \multicolumn{4}{|l|}{ Vegetarian } \\
\hline Red meat appreciation & 0.53 & 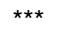 & 40.6 \\
\hline Health benefits of vegetarianism & 0.27 & 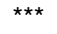 & 49.9 \\
\hline Education & -0.24 & $\star \star \star *$ & 55.5 \\
\hline Trust specialised media & -0.19 & $\star \star$ & 59.2 \\
\hline Number of vegetarian family members & 0.16 & * & 61.6 \\
\hline Recall of the promotion of meat & 0.16 & * & 64.0 \\
\hline Final $R^{2}(\%)$ & & & 64.0 \\
\hline
\end{tabular}

Health Benefits of Vegetarianism (Factor 2) included the prevention of disease, decreased saturated fat intake, and staying healthy in general. The final component focused on benefits of a less self-oriented, more altruistic nature, such as improvements in animal welfare, increased efficiency of food production, environmental improvement and decreases in Third World hunger (Factor 3, Animal Welfare, Environmental and Hunger Benefits of Vegetarianism).

Measures of internal reliability (Cronbach's alpha) indicated that all of the benefits of vegetarianism factors had high internal consistency (Table 3).

\section{Prediction of Meat is Unbealthy}

Overall, about half of the variance of the Meat is Unbealthy score was predicted by perceived benefits of vegetarian diets, being male, and by the presence of vegetarian family members (Table 4). The benefits of vegetarianism factor scores, particularly Peace and Contentment Benefits of Vegetarianism (16.3\% of the total variance), were the most important.

There were strong differences between the dietary groups. Social Concerns about Vegetarianism (positive predictor) ranked first for non-vegetarians.* This particular

"It should be noted that the results for the non-vegetarian group were very similar to the results for the general population (i.e. random sample only) regression analysis. This would be expected, as the majority of the population was non-vegetarian. Details of the results of the random sample only regression are available from the first author. barrier to vegetarianism factor consisted predominantly of beliefs held by respondents that they would be stereotyped negatively, thought of as a 'wimp' or not 'macho' enough, or feel conspicuous among others if they were to become vegetarian, and an unwillingness to eat unusual foods. Health Benefits of Vegetarianism ranked second, followed by the other benefits (all positive predictors).

Income was the strongest (negative) predictor for semivegetarians, followed by Universal Values (positive predictor). Universal Values is a personal values factor composed of items such as 'Unity with nature', 'A world of beauty', 'Protecting the environment' and 'Equality'.

More of the variance of Meat is Unbealthy (64\%) was explained among the vegetarian group than among any other dietary group or all respondents considered together. Red Meat Appreciation (enjoyment of eating meat) ranked first for vegetarians, with Health Benefits of Vegetarianism second (both positive predictors) and education third (negative predictor).

\section{Discussion}

We found that, for all respondents considered as a group, benefits of vegetarianism, particularly non-health benefits, were most strongly related to the belief that meat is unhealthy, but that the factors associated with this belief differed according to dietary group. For non-vegetarians, social concerns about vegetarianism were most important, 
followed by health and non-health benefits of vegetarianism. Income (negative) and universal values were the only predictors for semi-vegetarians, while for vegetarians, red meat appreciation, health benefits and education (negative) were the strongest predictors.

Although the majority of the South Australian population does not believe that meat is unhealthy, a significant minority does appear to hold this belief. For example, we found that $12 \%$ of non-vegetarian men and $10 \%$ of women believed that red meat is fattening, while $8 \%$ of non-vegetarian men and $6 \%$ of women believed that meat causes heart disease. (The figures were significantly lower for women, perhaps because women are less likely to be overweight and obese or to die from cardiovascular disease $^{38,39}$.) A recent Danish study has also found that some meat-eaters may consider meat to be unhealthy ${ }^{40}$. The factors associated with the belief that meat is unhealthy should be of interest to those who wish to promote meat, meat-free diets, or plant-based diets that include some meat.

For all of the respondents, the perceived benefits of vegetarianism were important positive predictors of Meat is Unhealthy, as predicted (hypothesis 1), with Peace and Contentment Benefits of Vegetarianism being the key factor. This factor is quite diverse. It includes items that represent improved equality between the sexes, reduced aggression, religious and spiritual benefits, as well as increased dietary enjoyment, improved health and environmental improvement. The results also show a strong positive association between beliefs about the unhealthiness of meat and concern for animal welfare, food-production efficiency and the environment. Thus, the interaction between the health and non-health issues surrounding plant-based diets is important.

Health Benefits of Vegetarianism was also an important predictor of Meat is Unbealthy, particularly for the nonvegetarian and vegetarian groups. If vegetarianism is thought to decrease fat intake, prevent disease and improve health in general, it is logical that it would be associated with the factor that includes such beliefs as eating meat increases fat intake and disease.

Social issues were also important for the non-vegetarian group, for whom Social Concerns about Vegetarianism was the strongest - and a positive - predictor. It was not expected that barriers to the adoption of vegetarianism would be positively associated with the belief that meat is unhealthy (hypothesis 2). One explanation could be that those who believe meat is unhealthy need justification for their meat-eating behaviour. This accords with cognitive dissonance theory and balance theory, which suggest that people may alter their beliefs in order to justify their behaviour ${ }^{41-43}$. Alternatively, perhaps it simply highlights the strength of the social barriers to vegetarianism for many people: even when meat is believed to be unhealthy, dietary change may not occur unless social and other issues are overcome.
At first glance, it appears odd that Red Meat Appreciation was a positive predictor of Meat is Unbealthy for vegetarians. This group, apart from two people, all had negative scores for Red Meat Appreciation. Thus, as vegetarians become less strongly negative about meat appreciation, the more they agree that meat is intrinsically unhealthy. One explanation is that the mildly negative people may need more justification for their non-meateating actions, in accordance with cognitive dissonance theory and balance theory ${ }^{41-43}$. Thus, these people may be vegetarian more for health reasons than because of any strong dislike of eating meat. A longitudinal study is required to assess the likelihood of this being the case for vegetarians.

It is interesting that income and education were negative predictors of Meat is Unbealthy for semivegetarians and vegetarians, respectively. Apart from the less important predictor of being male (for all respondents and for non-vegetarians), these were the only demographic variables that were predictors. Nutrition knowledge generally increases with higher education and income level $^{44,45}$. Probably people with higher nutrition knowledge are less likely to agree that meat causes cancer or heart disease and/or may see some health benefits of eating meat despite their personal low or nil meat consumption. The more highly educated vegetarian and higher-income semi-vegetarian respondents may have reasons for their dietary behaviour other than a perception that meat is unhealthy. They may emphasise the health benefits of plant-based diets rather than the negative health effects of meat, or they may be semivegetarian or vegetarian for environmental, animal welfare or other non-health reasons. Clearly this finding requires further investigation.

The present findings have important public health implications. Negative beliefs about the healthiness of meat were associated with perceived benefits of vegetarianism and social concerns about vegetarianism. The benefits include not only health benefits, but also environmental, animal welfare, peace and contentment benefits. Plant-based diets are becoming more widely acknowledged as providing health benefits, including decreases in the risk of particular diseases ${ }^{7,8}$. However, the misconceptions held by some consumers that meat is the cause of such diseases needs to be overcome. More accurate information about the positive attributes of meat and of the benefits of plant-based diets is required, but in the context of the broader issues that surround meat. Future research could examine the nature and accuracy of the available information about meat from a variety of sources, to determine where change is needed.

The cross-sectional study design we utilised was necessary to examine current associations between people's beliefs about the healthiness of meat and other factors such as perceived benefits of vegetarianism. However, it is difficult to interpret the observed associations without a 
longitudinal study design that examines how people change over time. This is because it is not clear whether the various beliefs and factors such as the perceived benefits and barriers of vegetarianism led to the specific belief that meat is unhealthy or vice versa. More extensive qualitative work is also important, as it could uncover any presently unknown intermediary factors that may influence beliefs about meat. These are promising avenues for future research.

\section{Conclusion}

We found that negative beliefs about the health aspects of meat were linked predominantly to the perceived benefits of vegetarianism for all respondents considered as a group and, to a lesser extent, for non-vegetarians and vegetarians. For non-vegetarians it was social concerns about vegetarianism and health benefits that were most important, while for vegetarians it was red meat appreciation and health benefits of vegetarianism that were important. To influence meat consumption via beliefs about the healthiness of meat it is important to address social, environmental, animal welfare, peace and contentment issues as well as health.

\section{References}

1 Sanders TAB. The nutritional adequacy of plant-based diets. Proc. Nutr. Soc. 1999; 58: 265-9.

2 National Health and Medical Research Council. Dietary Guidelines for Australians. Canberra: Australian Government Publishing Service, 1992.

3 US Department of Health and Human Services. Healthy People 2010 - Conference Edition. Washington, DC: US Department of Health and Human Services, 2000.

4 World Cancer Research Fund/American Institute for Cancer Research. Food, Nutrition and the Prevention of Cancer: $A$ Global Perspective. Washington, DC: American Institute for Cancer Research, 1997.

5 American Dietetic Association. Position of the American Dietetic Association: vegetarian diets. J. Am. Diet. Assoc. 1997; 97(11): 1317-21.

6 Bingham SA. High-meat diets and cancer risk. Proc. Nutr. Soc. 1999; 58: 243-8.

7 Key TJ, Davey GK, Appleby PN. Health benefits of a vegetarian diet. Proc. Nutr. Soc. 1999; 58: 271-5.

8 Key TJ, Fraser GE, Thorogood M, Appleby PN, Beral V, et al. Mortality in vegetarians and nonvegetarians: detailed findings from a collaborative analysis of 5 prospective studies. Am. J. Clin. Nutr. 1999; 70(Suppl.): 516S-24S.

9 Appleby PN, Thorogood M, Mann JI, Key TJA. The Oxford Vegetarian Study: an overview. Am. J. Clin. Nutr. 1999; 70(Suppl.): 525S-31S.

10 Mann JI. Optimizing the plant-based diet. Asia Pacific J. Clin. Nutr. 2000; 9(Suppl. 1): 60S-4S.

11 Dwyer JT. Nutritional consequences of vegetarianism. Annu. Rev. Nutr. 1991; 11: 61-91.

12 Alexander D, Ball MJ, Mann J. Nutrient intake and haematological status of vegetarians and age-sex matched omnivores. Eur. J. Clin. Nutr. 1994; 48: 538-46.
13 Dwyer JT. Health aspects of vegetarian diets. Am. J. Clin. Nutr. 1988; 48: 712-38.

14 Fieldhouse P. Food and Nutrition: Customs and Culture. London: Croom Helm, 1986.

15 Lewis S. An opinion on the global impact of meat consumption. Am. J. Clin. Nutr. 1994; 59(Suppl.): 1099S$102 \mathrm{~S}$.

16 Pimentel D, Houser J, Preiss E, White O. Water resources: agriculture, the environment, and society. BioScience 1997; 47(2): 97-106.

17 Spedding CRW. The effect of dietary changes on agriculture. In: Lewis B, Assmann G, eds. The Social and Economic Contexts of Coronary Prevention. London: Current Medical Literature, 1990.

18 Sapp SG. Impact of nutritional knowledge within an expanded rational expectations model of beef consumption. J. Nutr. Educ. 1991; 23(5): 214-22.

19 Lea $\mathrm{E}$, Worsley A. Influences on meat consumption in Australia. Appetite 2001; 36(2): 127-36.

20 Richardson NJ, Shepherd R, Elliman NA. Current attitudes and future influences on meat consumption in the UK. Appetite 1993; 21: 41-51.

21 Worsley A, Skrzypiec G. Do attitudes predict red meat consumption among young people? Ecol. Food Nutr. 1998; 37: $163-95$

22 Cox DN, Anderson AS, Lean MEJ, Mela DJ. UK consumer attitudes, beliefs and barriers to increasing fruit and vegetable consumption. Public Health Nutr. 1998; 1(1): 61-8.

23 Lappalainen R, Saba A, Holm L, Mykkanen H, Gibney MJ. Difficulties in trying to eat healthier: descriptive analysis of perceived barriers for healthy eating. Eur. J. Clin. Nutr. 1997; 51(Suppl. 2): 36S-40S.

24 Rosenstock IM. Historical origins of the Health Belief Model. Health Educ. Monographs 1974; 2(4): 328-35.

25 Wolinsky FD. The Sociology of Health: Principles, Professions and Issues. Boston, MA: Little/Brown, 1980.

26 McIntosh WA, Kubena KS, Jiang H, Usery CP, Karnei K. An application of the Health Belief Model to reductions in fat and cholesterol intake. J. Wellness Perspectives 1996; 12(2): 98-107.

27 Dillman DA. Mail and Telephone Surveys: The Total Design Method. Washington, DC: John Wiley and Sons, 1978.

28 Fiddes N. Meat: A Natural Symbol. London: Routledge, 1991.

29 Freeland-Graves J, Greninger SA, Graves GR, Young RK. Health practices, attitudes, and beliefs of vegetarians and nonvegetarians. J. Am. Diet. Assoc. 1986; 86(7): 913-8.

30 McIntosh WA, Fletcher RD, Kubena KS, Landmann WA. Factors associated with sources of influence/information in reducing red meat by elderly subjects. Appetite 1995; 24: 219-30.

31 Schwartz SH. Universals in the content and structure of values: theoretical advances and empirical tests in 20 countries. Adv. Exp. Soc. Psychol. 1992; 25: 1-65.

32 Worsley A, Baghurst K, Skrzypiec G. Meat Consumption and Young People. CSIRO Final Report to the Meat Research Corporation. Adelaide: CSIRO, 1995.

33 Kearney M, Gibney MJ, Martinez JA, de Almeida MDV, Friebe D, et al. Perceived need to alter eating habits among representative samples of adults from all member states of the European Union. Eur. J. Clin. Nutr. 1997; 51(Suppl. 2): $30 S-5 S$.

34 Worsley A, Scott V. Consumers' concerns about food and health in Australia and New Zealand. Asia Pacific J. Clin. Nutr. 2000; 9(1): 24-32.

35 Australian Bureau of Statistics. Basic Community Profile software. 1996 Census of Population and Housing. Canberra: Australian Bureau of Statistics, 1996. 
36 Worsley A, Skrzypiec G. Teenagers' social attitudes and red meat consumption. Proceedings of the Royal Society of New Zealand. Miscellaneous Series 36. Wellington: Royal Society of New Zealand, 1996.

37 Vegetarian Society UK. Summary of RealEat polls 19841999 [Online]. Available at http://www.vegsoc.org/info/ realeat.html. 2001.

38 Australian Bureau of Statistics. National Nutrition Survey Selected Highlights Australia 1995. Canberra: Australian Government Publishing Service, 1997.

39 Australian Bureau of Statistics. Australia Now - A Statistical Profile: Health [Online] Available at http://www.abs. gov.au/. 2000.

40 Holm L, Møhl M. The role of meat in everyday food culture: an analysis of an interview study in Copenhagen. Appetite 2000; 34: 277-83.

41 Frey D. Recent research on selective exposure to information. Adv. Exp. Soc. Psychol. 1986; 19: 41-80.

42 Heider F. Social perception and phenomenal causality. Psychol. Rev. 1944; 51: 358-74.

43 Festinger L. A Theory of Cognitive Dissonance. Stanford, CA: Stanford University Press, 1957.

44 Parmenter K, Waller J, Wardle J. Demographic variation in nutrition knowledge in England. Health Educ. Res. 2000; 15(2): 163-74.

45 Variyam JN, Blaylock J, Smallwood DM. Modelling nutrition knowledge, attitudes, and diet-disease awareness: the case of dietary fibre. Stat. Med. 1996; 15(1): 23-35. 